\title{
Analysis of Patients Visiting Niigata University Medical and Dental Hospital with Chief Complaints of Metal Allergy and/or Focal Infection in the Previous 8 Years
}

\author{
Yosuke Akiba \\ Ken Tomizuka \\ Masaru Kaku \\ Maiko Kawasaki \\ Masako Nagasawa \\ Ryohei Takano \\ Katsumi Uoshima \\ Division of Bio-Prosthodontics, \\ Niigata University Graduate School of Dental Science, Niigata, Japan \\ E-mail:yoakiba@dent.niigata-u.ac.jp \\ Received November 10, 2010; Accepted December 18, 2010
}

\begin{abstract}
Dental metal allergy and dental focal infection are possible causes of dermatological diseases, but have been the subjects of few reports to date. We have been treating such patients in our special clinic for more than 20 years. The purpose of the present study was to investigate the mouths of patients visiting our dental hospital over an 8-year period, with the aim of clarifying whether dental metal allergy and/or dental focal infection affects their dermatologic conditions. We surveyed all clinical records of the 185 patients who visited Niigata University Medical and Dental Hospital with chief complaints of dental metal allergy since 2002. Diagnostics of skin diseases, periodontal records, periapical lesions, dental caries, dental metal series patch test results and Electron Probed Micro-Analysis (EPMA) data were investigated. Ninety-two (49\%) patients were suffering from pustulosis palmaris et plantaris and 20 (11\%) patients had lichen planus. Eighty-two (49\%) patients showed positive reactions on patch testing. Based on the result of patch tests, $\mathrm{Ni}$ showed the highest positivity rate (62\%, 51 patients), but on EPMA, the number of patients with $\mathrm{Ni}$ as an allergen was 14 (27\%). On the other hand, more than $98 \%$ of patients who showed positive reactions on patch test to $\mathrm{Pd}$ and $\mathrm{Au}$ had these metals in their dental prostheses. In addition, $112(60 \%)$ patients showed the possibility of dental focal infections.
\end{abstract}

Keywords: Dental metal allergy, dental focal infection.

\section{Introduction}

Numerous Japanese currently suffer from allergic reactions to various substances, including chemicals, drugs, and metals. Dentists in particular have to be aware that the use of many materials, including metals, may cause severe allergic reactions.

The possibility of dental metal allergy was first introduced in $1928^{1}$ and many clinical studies have since been published in Scandinavia and Japan ${ }^{2,3}$. However, the notion remains poorly understood 
in other parts of the world, and this is probably why research in this field is lacking. Therefore, it is of great importance to clarify the mechanisms of allergic reaction caused by dental metals in order to appropriately treat these patients.

As noted above, the etiology of metal allergy is poorly understood, despite recent increases in the number of patients in Japan. The major symptom of metal allergy is contact dermatitis, and this includes pustulosis palmoris et plantaris (PPP) and oral lichen planus (OLP). Metal ions alone do not act as allergens but haptens, which induce allergic reactions only when they interact with larger molecules ${ }^{4}$. Moreover, metal ions such as copper or zinc are indispensable to life, and these are typically consumed in foods or beverages. Nevertheless, these ions may be the cause of allergic reactions. Chronic inflammation in the body is also known to exacerbate symptoms ${ }^{5,6}$. These factors complicate elucidation of the sensitization pathways. In addition to better understanding of the causes of metal allergy, collection of as much clinical data as possible is necessary in order to understand the current state of the disease.

We established the dental metal allergy clinic approximately 20 years ago and have since been accepting putative patients. The purpose of this study was to summarize the patients visiting our clinic with dental metal allergy since 2002. In each patient, we investigated the state of the oral cavity and relationships between the presence of metal ion allergy, chronic inflammation and other symptoms and factors.

\section{Materials and Methods}

\section{Patients}

In this study, patients who were referred to or visiting our hospital for testing, diagnosis, and treatment because of suspected dental metal allergy were selected from the clinical database of our allergy clinic in Niigata University Medical and Dental Hospital during the period between April 1, 2002 and January 31, 2010.

\section{Investigated Items}

Investigated items were gender, age, oral chronic inflammation including oral caries, periodontal disease, and periapical lesions, results of dental metal series patch test, Electron Probe MicroAnalysis (EPMA) and diagnostics of skin disease.

For investigation of oral chronicinflammation, we carried out oral examination with $\mathrm{X}$-ray examination and probing for measurement of periodontal pocket depth.

Skin diseases were diagnosed by a dermatologist at Niigata University Medical and Dental Hospital, and patch test was carried out. Patients were patch tested with 20 ready-made reagents shown in Table 1 (Torii Pharmaceutical Corporation, Tokyo, Japan). Skin reactions were observed at 2, 3, and 7 days, and were evaluated according to the International Contact Dermatitis Research Group (ICDRG) standards (Table 2).

Prosthetic metal materials were analyzed by EPMA (EPMA-1610, Shimadzu, Japan), which was performed in patients showing positive results on patch test. Metal samples were collected by sand paper scraping without damage to prostheses.

This survey was performed in accordance with the ethical guidelines for epidemiologic research under the Helsinki accord, and with the permission of the Niigata University Ethics Committee.

Table 1. Patch-test reagents.

\begin{tabular}{clllllll}
\hline No & Metals & $\%$ & Base & No & Metals & $\%$ & Base \\
\hline 1 & $\mathrm{CoCl}_{2}$ & 0.5 & $\mathrm{Aq}$ & 11 & $\mathrm{SnCl}_{2}$ & 1.0 & $\mathrm{Aq}$ \\
2 & $\mathrm{NiSO}_{4}$ & 2.5 & $\mathrm{Aq}$ & 12 & $\mathrm{CuSO}_{4}$ & 1.0 & $\mathrm{Aq}$ \\
3 & $\mathrm{~K}_{2} \mathrm{Cr}_{2} \mathrm{O}_{7}$ & 0.5 & $\mathrm{Aq}$ & 13 & $\mathrm{FeCl}_{3}$ & 2.0 & $\mathrm{Aq}$ \\
4 & $\mathrm{HgCl}_{2}$ & 1.0 & $\mathrm{Aq}$ & 14 & $\mathrm{AlCl}_{3}$ & 2.0 & $\mathrm{Aq}$ \\
5 & $\mathrm{HAuCl}_{4}$ & 0.5 & $\mathrm{Aq}$ & 15 & $\mathrm{InCl}_{3}$ & 1.0 & $\mathrm{Aq}$ \\
6 & $\mathrm{ZnCl}_{2}$ & 0.5 & $\mathrm{Pet}$ & 16 & $\mathrm{IrCl}_{4}$ & 1.0 & $\mathrm{Aq}$ \\
7 & $\mathrm{MnCl}_{2}$ & 0.5 & $\mathrm{Pet}$ & 17 & $\mathrm{TiO}_{2}$ & 0.5 & Pet \\
8 & $\mathrm{AgBr}_{2}$ & 2.0 & $\mathrm{Pet}$ & 18 & $\mathrm{SbCl}_{3}$ & 1.0 & Pet \\
9 & $\mathrm{PdCl}_{2}$ & 1.0 & $\mathrm{Aq}$ & 19 & $\mathrm{MoCl}_{5}$ & 1.0 & $\mathrm{Aq}$ \\
10 & $\mathrm{H}_{2} \mathrm{PtCl}_{6}$ & 0.5 & $\mathrm{Aq}$ & 20 & $\mathrm{CdSO}_{4}$ & 1.0 & $\mathrm{Aq}$ \\
\hline
\end{tabular}


Table 2. International Contact Dermatitis Research Group Standard.

\begin{tabular}{cl}
\hline Grade & Meaning/appearance \\
\hline- & Negative \\
$+?$ & Doubtful reaction \\
+ & Weak (non-vesicular) reaction \\
++ & Strong (edematous or vesicular) reaction) \\
+++ & Extrem reaction \\
IR & Irritant reaction \\
\hline
\end{tabular}

\section{Results and Discussion}

\section{Subjects}

The number of patients who were suspected of having a dental metal allergy was 185 (63 male, 122 female), and the male/female ratio was about 1:2. The mean patient age was 52 years (male patients, 51.5 years; female patients, 52.3 years). Patient age distribution is shown in Figure 1.Most male patients were in their 60s (20 patients, 20/63:31\%), followed by the 50 s (13 patients, $13 / 63,20 \%$ ) and 40 s (10 patients, 10/63, 16\%). Meanwhile, most female patients were in their 50 s (36 patients, 36/122, 30\%), followed by the 60s (24 patients, 24/122, 20\%), 30s (23 patients, 23/122, 19\%) and 40s (18 patients, $18 / 122,15 \%)$.

\section{Disease distribution}

The dermatologist diagnosed 92 patients (92/185, $49 \%)$ as having PPP and 20 patients $(20 / 185$, $11 \%)$ as having OLP. Eleven patients (11/185, 6\%) were diagnosed as having contact dermatitis, and other patients were diagnosed with eczema dyshidrosiforme, cheilitis, stomatitis, glossalgia, and atopic dermatitis (Table 3).

\section{Chronic inflammation}

Oral examination revealed that 98 patients (98/185, $53 \%)$ had periodontal disease and 55 patients (55/185, 30\%) had periapical lesions. The total number (ratio) of patients with periodontal disease and/or periapical lesions was 112 (112/185, 60\%).

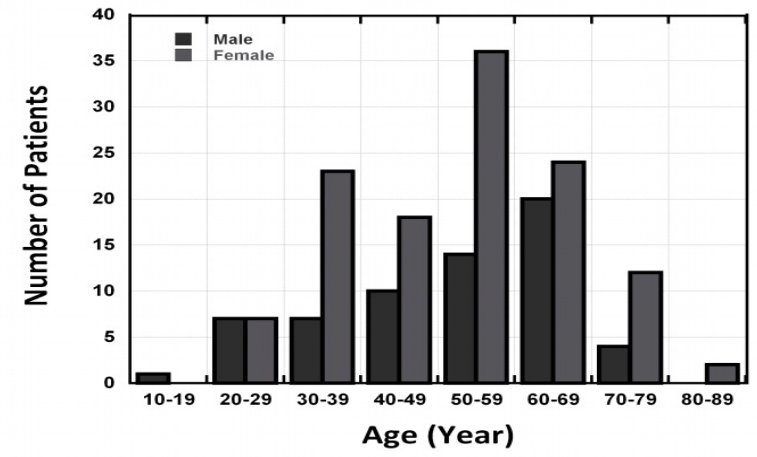

Figure 1. Age and gender distribution.

Table 3. Diagnoses, allergen metals, and chronic inflammation.

\begin{tabular}{|c|c|c|c|c|}
\hline Diagnosis & $\begin{array}{l}\text { Number } \\
\text { (M:F) } \\
\text { (ratio) }\end{array}$ & $\begin{array}{l}\text { Number } \\
\text { (ratio) of } \\
\text { patients } \\
\text { positive } \\
\text { for } \\
\text { allergen } \\
\text { metal }\end{array}$ & $\begin{array}{l}\text { Allergen } \\
\text { metals } \\
\text { (number, } \\
\text { ratio) }\end{array}$ & $\begin{array}{l}\text { Chronic } \\
\text { inflammation }\end{array}$ \\
\hline $\begin{array}{l}\text { Pustulosis } \\
\text { palmaris et } \\
\text { plantaris }\end{array}$ & $\begin{array}{l}92 \\
(30: 62) \\
(49 \%)\end{array}$ & $41(45 \%)$ & $\begin{array}{l}\operatorname{Pd}(16,39 \%) \\
\operatorname{Au}(14,34 \%) \\
\operatorname{Cr}(8,19 \%)\end{array}$ & 57 (62\%) \\
\hline $\begin{array}{l}\text { Oral lichen } \\
\text { planus }\end{array}$ & $\begin{array}{l}20 \\
(5: 15) \\
(11 \%)\end{array}$ & $10(50 \%)$ & $\begin{array}{l}\operatorname{Au}(7,35 \%) \\
\operatorname{Pd}(3,15 \%) \\
\operatorname{Cr}(3,15 \%)\end{array}$ & $14(70 \%)$ \\
\hline $\begin{array}{l}\text { Contact } \\
\text { dermatitis }\end{array}$ & $\begin{array}{l}11 \\
(6: 5) \\
(6 \%)\end{array}$ & 7 (64\%) & $\begin{array}{l}\mathrm{Pd}(4,36 \%) \\
\mathrm{Au}(3,27 \%)\end{array}$ & 9 (82\%) \\
\hline
\end{tabular}

Note: M:F= Male:Female.

\section{Allergen, dental focal infection, and disease}

The male/female ratio among 92 PPP patients was $1: 2$ and the number of patients with at least one allergen metal was $41(41 / 92,45 \%)$. The most frequently positive allergen metals were palladium and gold. The number of patients who had putative focal infection was 57 (57/92, 62\%).

Among the 20 OLP patients, male/female ratio was 1:3, and the number of patients who had at least one allergen metal was $10(10 / 20,50 \%)$. The most frequently positive allergen metal was gold, 
and the number of patients who had putative focal infection was 14 (14/20, 70\%).

Among the 11 contact dermatitis patients, the male/female ratio was $1: 1$. The number of patients who had at least one allergen metal was 7 (7/11, $64 \%)$, and the most frequently positive allergen metals were palladium and gold. The number of patients who showed putative focal infection was 9 (9/11, 82\%).

\section{Patch-test and EPMA}

The number of patients who underwent patch testing was 166 (Figure 2). Positive patch test reactions were seen in 82 patients $(82 / 166,49 \%)$, including
27 males $(27 / 82,33 \%)$ and 55 females (55/166, $67 \%)$. The metal ions with the highest positive reaction rates were nickel (51 patients, 51/82, 62\%), chromium (49 patients, 49/82, 59\%), platinum (48 patients, 48/82, 59\%), cobalt (45 patients, 45/82, $54 \%$ ), gold (35 patients, 35/82, 43\%), and palladium (32 patients, 32/82, 39\%).

The most frequent constituents found in 174 patients mouths as a result of EPMA analysis (Figure 3) were found positive with silver (172 patients, 172/174, 99\%), copper (170 patients, 170/174, $98 \%)$, zinc (170 patients, 170/174, 98\%), gold (168 patients, 168/174, 97\%), palladium (166 patients, 166/174, 95\%), and indium (162 patients, 162/174, $93 \%)$.

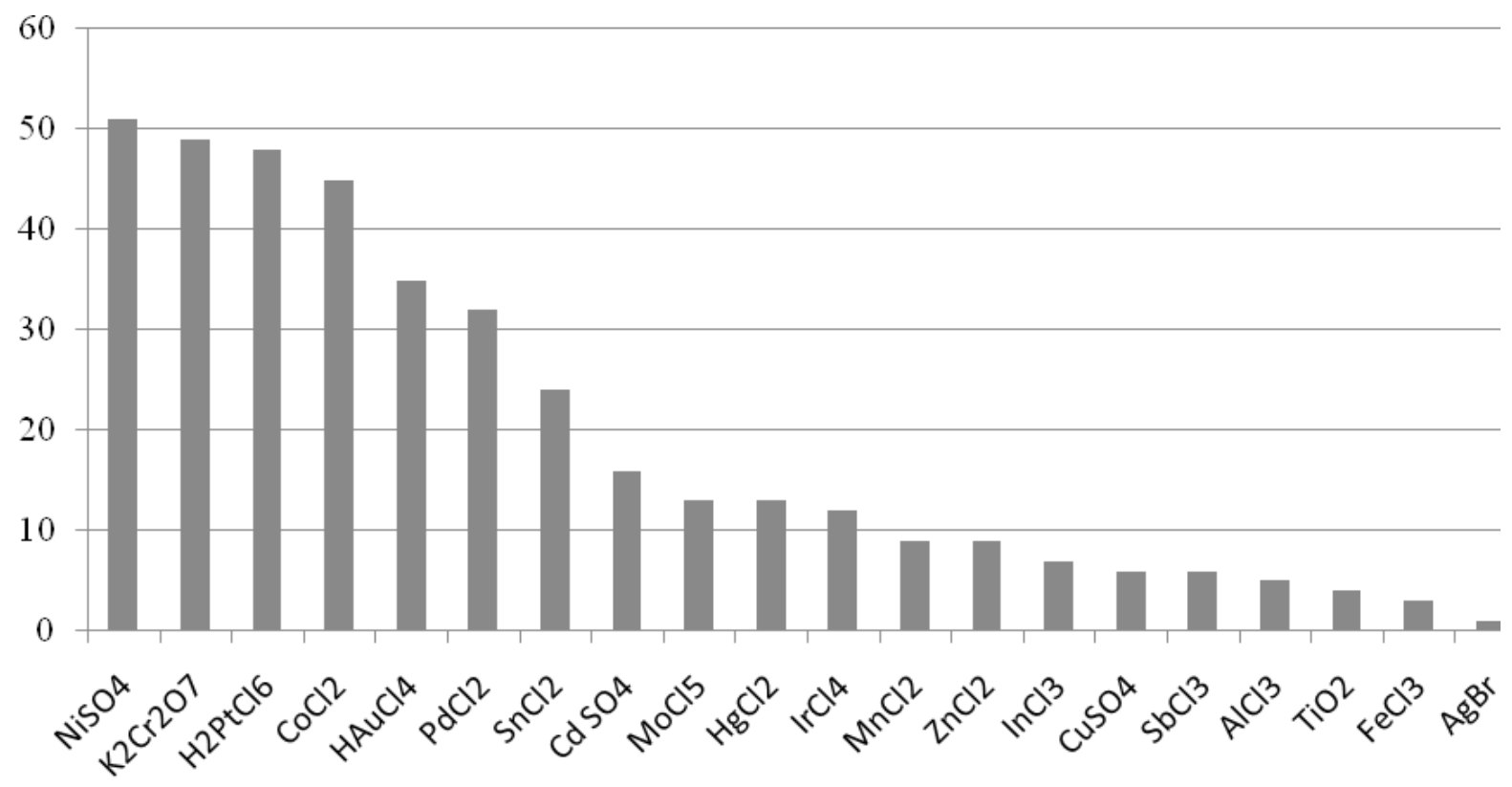

Reagent

Figure 2. Patch-test results with dental metal series. 
Akiba et al.

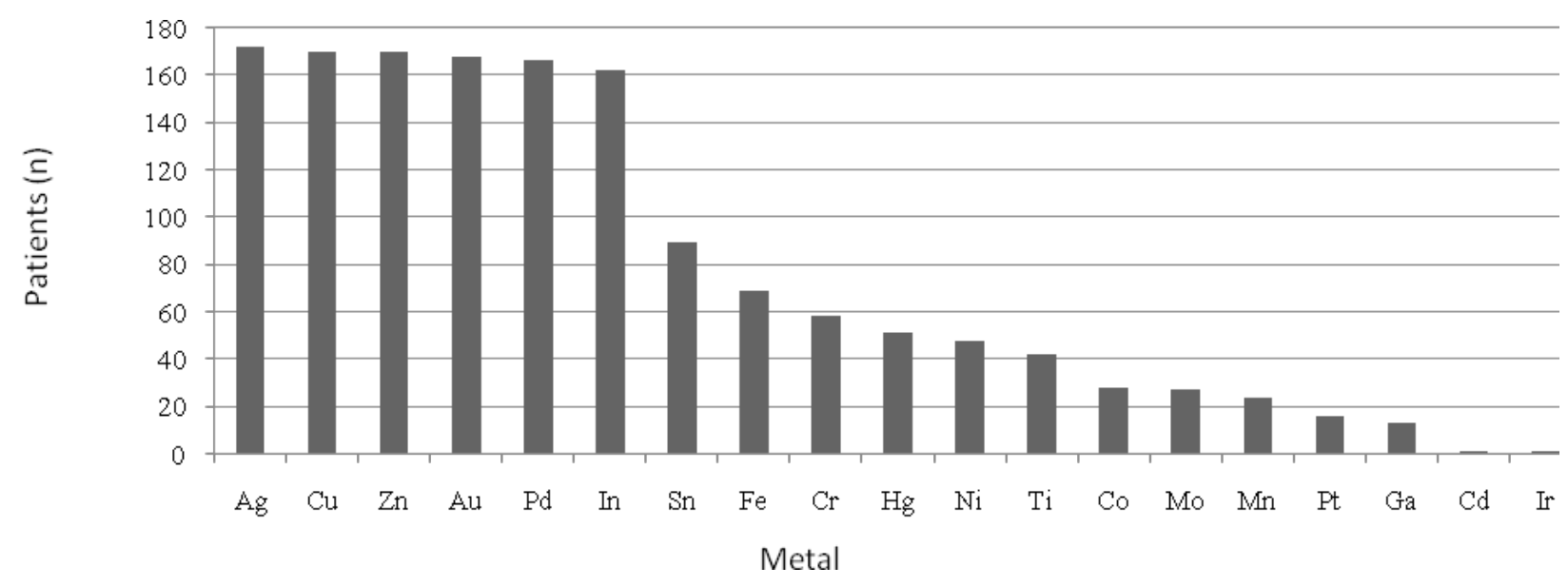

Figure 3. Results of EPMA analysis.

The co-incidence of patch test-positive metal ions and ions detected on EPMA analysis differed from the independent results as shown in Table 4. Metal ions that showed the highest co-incidence rates were thought to be the most likely allergens, and included palladium (32 patients, 32/32, 100\%), gold (33 patients, 33/35, 94\%), chromium (19 patients, 19/49, 39\%).

Table 4. Ratio of allergens present in prostheses.

\begin{tabular}{cccr}
\hline Metal & $\begin{array}{c}\text { Number of } \\
\text { patients with } \\
\text { positive reaction } \\
\text { on patch test }\end{array}$ & $\begin{array}{c}\text { Number of } \\
\text { patients with } \\
\text { allergen in their } \\
\text { prostheses }\end{array}$ & Ratio \\
\hline $\mathrm{Ni}$ & 51 & 14 & $27 \%$ \\
$\mathrm{Cr}$ & 49 & 19 & $39 \%$ \\
$\mathrm{Pt}$ & 48 & 2 & $4 \%$ \\
$\mathrm{Co}$ & 45 & 7 & $16 \%$ \\
$\mathrm{Au}$ & 35 & 33 & $94 \%$ \\
$\mathrm{Pd}$ & 32 & 32 & $100 \%$ \\
$\mathrm{Sn}$ & 23 & 14 & $61 \%$ \\
$\mathrm{Cd}$ & 15 & 0 & $0 \%$ \\
$\mathrm{Mo}$ & 13 & 0 & $0 \%$ \\
$\mathrm{Hg}$ & 13 & 1 & $8 \%$ \\
$\mathrm{Mn}$ & 9 & 0 & $0 \%$ \\
$\mathrm{Zn}$ & 8 & 7 & $88 \%$ \\
$\mathrm{In}$ & 7 & 7 & $100 \%$ \\
$\mathrm{Cu}$ & 6 & 6 & $100 \%$ \\
$\mathrm{Sb}$ & 5 & 0 & $0 \%$ \\
$\mathrm{Ti}$ & 4 & 2 & $50 \%$ \\
$\mathrm{Fe}$ & 3 & 2 & $67 \%$ \\
$\mathrm{Ag}$ & 1 & 1 & $100 \%$ \\
\hline
\end{tabular}

The male/female ratio of patients who visited our clinic with dental metal allergy during the investigated period was 1:2, similar to a previously identified trend ${ }^{3,7}$. There have been no reports to date identifying the reasons for such a gender-based difference, but it might have simply been due to a difference in available time to visit the hospital, as the proportion of women who do not work during the day is larger in Japan. In addition, it is possible that because women tend to wear metal accessories for longer periods, they may have a higher degree of sensitization. However, the fact that the average age was almost the same in male and female patients largely rules these reasons out. In terms of the age distribution among the patients, the increase in female patients with age indicates that sensitization to dental metal ions takes a long period of time, but it is possible that dental metals can cause allergic reactions even after long periods of time.

Among the 185 patients included in this study, 92 were suffering from PPP, a much higher proportion than in previous reports ${ }^{3,7-9}$. This was probably because several reports have indicated the relationship between PPP and dental metal allergy and/or chronic inflammation, and many patients and dermatologists are now aware of this relationship. PPP and OLP, as well as contact dermatitis, are reported to be effectively treated by allergen removal and/or oral prophylaxis. In contrast, few patients were diagnosed with atopic dermatitis. This may have been because dermatologists at our 
hospital believe that it is more difficult to relate atopic dermatitis and dental metal allergy.

A total of $61 \%$ of patients were confirmed to have periodontal disease and/or periapical lesions. Even though this rate is very high, it does not necessarily mean that chronic inflammation is the cause of allergic symptoms. It may be necessary to compare the rate of chronic inflammation between allergic patients and a control group with no such symptoms.

It is thought that chronic inflammation, such as tonsillitis, may be related to the etiology of PPP. However, within the limitations of this study, we were unable to identify any correlation between these conditions among our patients. At the same time, we were unable to identify a clear causative relationship between metal ions and disease. Further investigation is thus needed.

Nickel was the most frequent metal ion to give positive results on the patch test; this is the same result as in previous reports. This is probably because human beings tend to show long and frequent exposure to nickel. Nickel has been used in plated commodities and cosmetics, and it has since been reported that nickel hypersensitivity is one of the most common metal allergy. Dentists therefore should avoid using nickel in dental treatments. It was recently reported that nickel ions triggered an inflammatory response by directly activating human toll-like receptor 4 , and this could a reasonable explanation for the high positivity rate for nickel on the patch test ${ }^{10}$.

In Japan, palladium alloy is most commonly used metal in dentistry because the Japanese health insurance system allows using the alloy. Many of the metal ions showing high co-incidence between the patch test and EPMA results are used as dental alloy constituents. We should therefore consider substituting these with non-allergenic materials, even when patients do not show clear symptoms. The continued use of these metals may increase the number of allergic patients in the future.

\section{Conclusion}

In the present study, we investigated patients with complaints thought to be related to dental metal allergies. However, the number of patients was quite limited, and it was difficult to clearly identify the contribution of metal ions and/or chronic inflammation to diseases. We must therefore continue to collect precise data on such patients in order to elucidate the etiology and provide appropriate treatment.

\section{Conclusion}

Clinical records of the 185 patients who visited Niigata University Medical and Dental Hospital with chief complaints of dental metal allergy since 2002 showed $49 \%$ patients were suffering from pustulosis palmaris et plantaris and $11 \%$ patients had lichen planus. Meanwhile, $49 \%$ patients showed positive reactions on patch testing. It was shown that Nihad the highest positivity rate, but on EPMA, the number of patients with $\mathrm{Ni}$ as an allergen was $27 \%$. On the other hand, more than $98 \%$ of patients showed positive reactions on patch test to $\mathrm{Pd}$ and $\mathrm{Au}$, and had these metals in their dental prostheses. In addition, $60 \%$ patients showed the possibility of dental focal infections.

\section{References}

1. Fleischmann P. 1928. Zur Frage der Gefahrichkeit Kleinster Quecksilbermengen. Dtsch. Med. Woschen Scher. 54: 304.

2. Magnusson B, Bergman M, Bergman B, Soremark R. 1982. Nickel allergy and nickel-containing dental alloys.Scand J Dent Res 90: 163-7.

3. Hamano H, Uoshima K, Miao WP, Masuda T, Hani M, Kitazaki H, Inoue M. 1998. Investigation of metal allergy to constituent elements of intraoral restration materials. Kokubyo Gakkai Zasshi65(1): 93-9.

4. Budinger L, Hertl M. 2000. Immunologic mechanisms in hypersensitivity reaction to metal ions: an overview. Allergy 55: 108-55.

5. Ueda Y, Shiota S. 1991. Clinical studies on the dental focal infection, interrelationship of a skin disease, pustulosis palmaris et plantaris. Jpn J Oral Diag Oral Med 4: 464-8.

6. Yamamoto $Y$, Hashimoto A, Togashi $K$, Takatsuka S, Ito A, Shimura H, Ito M. 2001. Effect of treatment for dental focal infection on 
Akiba et al.

pustulosis palmaris et plantaris.Jpn J Dermatol 111: 821-6.

7. Kobayashi Y, Hashimoto A, Kogure J, Nomura S. 2004. The changes of the positive sensitization and allergen carrier rates in cases of suspected allergy to dental metals at our hospital. Niigata Dent J 34(1): 35-9.

8. Higuchi S, Sato H, Okuda R, Komatsu M. 2005. Study on 280 case of dental metal allergy related patients. Jpn J Conservative Dent 48(3): 399-412.
9. Hosoki M, Bando E, Asaoka K, Takeuchi H, Nishigawa K. 2009. Assessment of allergic hypersensitivity to dental materials. Bio-Med Mat Eng 19: 53-61.

10. Schmidt M, Raghavan B, Muller V, Vogl T, Fejer G, Tchaptchest S, Keck S, Goebeler M. 2010. Crucial role for human Toll-like receptor 4 in the development of contact allergy to nickel. Nature Immunology 11: 814-9. 